\title{
The Chaos Dynamic of Multiproduct Cournot Duopoly Game with Managerial Delegation
}

\author{
Fang Wu and Junhai Ma \\ College of Management and Economics, Tianjin University, Tianjin 300072, China \\ Correspondence should be addressed to Junhai Ma; mjhtju@aliyun.com
}

Received 19 December 2013; Revised 15 March 2014; Accepted 19 March 2014; Published 18 May 2014

Academic Editor: Mustafa Kulenović

Copyright ( 2014 F. Wu and J. Ma. This is an open access article distributed under the Creative Commons Attribution License, which permits unrestricted use, distribution, and reproduction in any medium, provided the original work is properly cited.

\begin{abstract}
Although oligopoly theory is generally concerned with the single-product firm, what is true in the real word is that most of the firms offer multiproducts rather than single products in order to obtain cost-saving advantages, cater for the diversity of consumer tastes, and provide a barrier to entry. We develop a dynamical multiproduct Cournot duopoly model in discrete time, where each firm has an owner who delegates the output decision to a manager. The principle of decision-making is bounded rational. And each firm has a nonlinear total cost function due to the multiproduct framework. The Cournot Nash equilibrium and the local stability are investigated. The tangential bifurcation and intermittent chaos are reported by numerical simulations. The results show that high output adjustment speed can lead to output fluctuations which are characterized by phases of low volatility with small output changes and phases of high volatility with large output changes. The intermittent route to chaos of Flip bifurcation and another intermittent route of Flip bifurcation which contains Hopf bifurcation can exist in the system. The study can improve our understanding of intermittent chaos frequently observed in oligopoly economy.
\end{abstract}

\section{Introduction}

Dynamic Cournot model is a typical nonlinear discrete time varying system which takes output as its decision variable. Some references investigated the nonlinear behaviors when some parameters are varied in oligarchic game, such as Flip and Hopf bifurcation. Wang and Ma [1] analyzed the Flip and Hopf bifurcations in a Cournot-Bertrand mixed model. Tramontana and Elsadany [2] proposed a three oligopoly market with heterogeneous expectations, analyzed double routes to chaos (Hopf and Flip bifurcation), and presented the differences of the two routes from the economic view. Besides the above, some researchers extended Cournot model to different forms according to the difference of the real economic environments. $\mathrm{Ma}$ and $\mathrm{Pu}$ [3] built a triopoly repeated game model based on heterogeneous expectations in which the market has quadratic inverse demand function and the firm possesses cubic total cost function. Xin et al. [4] built a nonlinear discrete output game model for two oligopolistic firms whose products are adnascent and investigated its complex dynamics. $\mathrm{Ma}$ and $\mathrm{Tu}$ [5] proposed a new dynamical Cournot duopoly game model with delayed bounded rationality in electricity market. Guo and $\mathrm{Ma}$ [6] studied the game model and complexity of retailer collecting and selling in closed-loop supply chain. Fanti et al. [7] analyzed the dynamic of a nonlinear Cournot duopoly with managerial delegation.

However, all above studies are limited in single-product firm. Dynamic oligopoly models lack the case of multiproduct firm. In productive practice, firms usually produce multiproducts rather than single products to obtain costsaving advantages, cater for the diversity of consumers' tastes, and provide a barrier to entry. For example, McDonalds can produce both hamburgers and French fries at a lower average cost than what it would cost two separate firms to produce the same goods.

At present, in most of the literature [1-6], producers are all based on the objective of maximum profit, but when ownership and management right are separate, managers are probably to manipulate the benefit for their personal purpose than just pure profit maximization. In order to make manager perform more aggressively in the market, the owner usually 
designs an incentive contract to exert a high level of effort of manager; for example, revenue $[8,9]$, sales $[10]$, market shares $[11,12]$, and relative profit $[7,13,14]$ are usually used as an optimal incentive scheme in management practice.

In the model of multiproduct framework, the most important problem is the structure of the cost function. In this research, the model uses a more general cost function which implies the concepts about economies of scope and economies of scale.

In this study, we build a duopoly multiproduct output model which extends the models of [1-7], which consider single-product firm, and introduce the managerial delegation to the multiproduct model which modifies the models of [1-6]. Then the existence of tangential bifurcation and intermittent chaos are proved by using numerical simulation experiments.

The plan of the paper is as follows. Section 2 presents the multiproduct game model with managerial delegation. Section 3 investigates the Cournot-Nash equilibrium and its local stability. Section 4 analyzed the properties of output dynamic in the nonlinear model by numerical simulation. Section 5 sums up briefly.

\section{The Model}

2.1. Relevant Concepts. In this part, we will introduce some concepts which the model includes.

\subsubsection{Economies of Scale and Diseconomies of Scale.} Economies of scale are the cost advantages that enterprises obtain due to size, throughput, or scale of operation. Economies of scale occur when long-run average cost falls as output increases $[15,16]$.

Diseconomies of scale are the forces that cause larger firms and governments to produce goods and services at increased per-unit costs. Diseconomies of scale occur when long-run average cost rises as output increases. The concept is the opposite of economies of scale $[15,16]$.

2.1.2. Economies of Scope and Diseconomies of Scope. Economies of scope is the situation in which the joint cost of producing two or more products is less than the sum of the separate costs of producing the products. If the sum of producing two or more products by separate firms is less than producing two or more products jointly by the same firm, diseconomies of scope are said to exist [15].

2.2. The Model. Consider two firms $i=1,2$, each of which produces two products, $a$ and $b$. The prices of the two products are given by

$$
\begin{aligned}
& p_{a}=l_{a}-\left(q_{1 a}+q_{2 a}\right)-k\left(q_{1 b}+q_{2 b}\right), \\
& p_{b}=l_{b}-\left(q_{1 b}+q_{2 b}\right)-k\left(q_{1 a}+q_{2 a}\right) .
\end{aligned}
$$

In (1), $i=1,2, j=a, b$, where $l_{j}>0, q_{i j}$ is the output of product $j$ produced by firm $i . k \in[-1,1]: k \in[-1,0)$ implies that products are complements; $k \in(0,1)$ implies products are alternative; products $a$ and $b$ are homogeneous when $k=1$; and each firm is a monopolist when $k=0$. The firms' products are perfect substitutes within each market ( $a$ or $b$ ) and are imperfect substitutes across markets.

The total cost functions of firms 1 and 2 are given as following:

$$
\begin{aligned}
C_{1}= & c_{1 a} q_{1 a}+c_{1 b} q_{1 b}+d_{1 a} q_{1 a}^{2}+d_{1 b} q_{1 b}^{2}+h_{1} q_{1 a} q_{1 b} \\
& -f_{1} q_{1 a}^{1 / 2} q_{1 b}^{1 / 2}+s_{1}+s_{1 a}+s_{1 b}, \\
C_{2}= & c_{2 a} q_{2 a}+c_{2 b} q_{2 b}+d_{2 a} q_{2 a}^{2}+d_{2 b} q_{2 b}^{2}+h_{2} q_{2 a} q_{2 b} \\
& -f_{2} q_{2 a}^{1 / 2} q_{2 b}^{1 / 2}+S_{2}+s_{2 a}+s_{2 b} .
\end{aligned}
$$

All parameters are assumed to be positive (see [15-17]). They are as follows:

$d_{i j}$ : diseconomies of scale;

$h_{i}$ : diseconomies of scope (see [17]);

$f_{i}$ : unit economies of scope, firm $i$ produces single product when $f_{i}=0$ (see [17]);

$S_{i}$ : nonproduct specific indivisible costs;

$s_{i j}$ : indivisible cost.

Each firm has an owner who delegates the output decision to its manager, and each owner picks an incentive contract (the objective function of manager) for the manager to maximize firm's profit. The profits of firms are as (3) describe, and they are owners' objective functions:

$$
\begin{aligned}
& \prod_{1}=p_{a} q_{1 a}+p_{b} q_{1 b}-C_{1}, \\
& \prod_{2}=p_{a} q_{2 a}+p_{b} q_{2 b}-C_{2} .
\end{aligned}
$$

Manager $i$ is told that his (her) salary includes a fixed salary and a bonus offered in the incentive contract; that is,

$$
T_{i}+U_{i} W_{i}
$$

$T_{i}$ and $U_{i}$ are constants. We can see that if the control variable is $q_{i j}$, maximizing $T_{i}+U_{i} W_{i}$ and maximizing $W_{i}$ are equivalent. So, we can consider $W_{i}$ as the objective function of manager. The objective function of manager $i$ can only belong to the following class (see [18]):

$$
W_{i}=r_{i} \prod_{i}+\left(1-r_{i}\right) F_{i} .
$$

Owner $i$ selects his (her) weighting coefficient $r_{i}$. At present, the forms of $F_{i}$ mainly include the incentives for sales which is proposed by Vickers (see [10]), incentives for revenue (see $[8,9]$ ), incentives for market shares (see $[11,12]$ ), and incentives for relative profit (see $[13,14])$. In this paper, we use relative profit as an incentive scheme. Thus, the managers' objective functions are as (6) describe

$$
\begin{aligned}
& W_{1}=r_{1} \prod_{1}+\left(1-r_{1}\right)\left(\prod_{1}-\prod_{2}\right), \\
& W_{2}=r_{2} \prod_{2}+\left(1-r_{2}\right)\left(\prod_{2}-\prod_{1}\right) .
\end{aligned}
$$


In (6), $0<r_{i}<2(i=1,2)$ implies the attitude of the manager. $r_{i}$ is exogenous variable which is exerted by owner as his contract before the game. If $r_{i} \in(0,1]$, the owner is interested in competitive, and if $r_{i} \in(1,2)$, the owner is interested in cooperative.

Two firms follow the bounded rational expectation which based on the local estimate of the marginal bonus as (7) describe:

$$
\begin{aligned}
& q_{1 a}^{\prime}=q_{1 a}+\alpha_{1} q_{1 a} \frac{\partial W_{1}}{\partial q_{1 a}}, \\
& q_{1 b}^{\prime}=q_{1 b}+\alpha_{2} q_{1 b} \frac{\partial W_{1}}{\partial q_{1 b}}, \\
& q_{2 a}^{\prime}=q_{2 a}+\beta_{1} q_{2 a} \frac{\partial W_{2}}{\partial q_{2 a}}, \\
& q_{2 b}^{\prime}=q_{2 b}+\beta_{2} q_{2 b} \frac{\partial W_{2}}{\partial q_{2 b}} .
\end{aligned}
$$

So, the dynamical system can be described as 4-dimension discrete difference equations as following form:

$$
\begin{aligned}
& q_{1 a}^{\prime}=q_{1 a}+\alpha_{1} q_{1 a} \\
& \times\left[r _ { 1 } \left(-2 q_{1 a}+l_{1}-q_{2 a}-k\left(q_{1 b}+q_{2 b}\right)-k q_{1 b}-c_{1 a}\right.\right. \\
& \left.-2 d_{1 a} q_{1 a}-h_{1} q_{1 b}+\frac{f_{1}}{2 q_{1 a}^{1 / 2} q_{1 b}^{1 / 2}}\right)+\left(1-r_{1}\right) \\
& \times\left(-2 q_{1 a}+l_{1}-k\left(q_{1 b}+q_{2 b}\right)-k q_{1 b}-c_{1 a}\right. \\
& \left.\left.-2 d_{1 a} q_{1 a}-h_{1} q_{1 b}+\frac{f_{1}}{2 q_{1 a}^{1 / 2} q_{1 b}^{1 / 2}}+k q_{2 b}\right)\right], \\
& q_{1 b}^{\prime}=q_{1 b}+\alpha_{2} q_{1 b} \\
& \times\left[r _ { 1 } \left(-k q_{1 a}-2 q_{1 b}+l_{2}-q_{2 b}-k\left(q_{1 a}+q_{2 a}\right)-c_{1 b}\right.\right. \\
& \left.-2 d_{1 b} q_{1 b}-h_{1} q_{1 a}+\frac{f_{1} q_{1 a}^{1 / 2}}{2 q_{1 b}^{1 / 2}}\right)+\left(1-r_{1}\right) \\
& \times\left(-k q_{1 a}-2 q_{1 b}+l_{2}-k\left(q_{1 a}+q_{2 a}\right)-c_{1 b}\right. \\
& \left.\left.-2 d_{1 b} q_{1 b}-h_{1} q_{1 a}+\frac{f_{1} q_{1 a}^{1 / 2}}{2 q_{1 b}^{1 / 2}}+k q_{2 a}\right)\right],
\end{aligned}
$$

$$
\begin{aligned}
& q_{2 a}^{\prime}= q_{2 a}+\beta_{1} q_{2 a} \\
& \times {\left[r _ { 2 } \left(-2 q_{2 a}+l_{1}-q_{1 a}-k\left(q_{1 b}+q_{2 b}\right)-k q_{2 b}-c_{2 a}\right.\right.} \\
&\left.-2 d_{2 a} q_{2 a}-h_{2} q_{2 b}+\frac{f_{2}}{2 q_{2 a}^{1 / 2} q_{2 b}^{1 / 2}}\right)+\left(1-r_{2}\right) \\
& \times\left(-2 q_{2 a}+l_{1}-k\left(q_{1 b}+q_{2 b}\right)-k q_{2 b}-c_{2 a}\right. \\
& q_{2 b}^{\prime}=q_{2 b}+\beta_{2} q_{2 b}\left.\left.-2 d_{2 a} q_{2 a}-h_{2} q_{2 b}+\frac{f_{2}}{2 q_{2 a}^{1 / 2} q_{2 b}^{1 / 2}}+k q_{1 b}\right)\right], \\
& \times\left[r_{2}\right.\left(-k q_{2 a}-2 q_{2 b}+l_{2}-q_{1 b}-k\left(q_{1 a}+q_{2 a}\right)-c_{2 b}\right. \\
&\left.\quad-2 d_{2 b} q_{2 b}-h_{2} q_{2 a}+\frac{f_{2} q_{2 a}^{1 / 2}}{2 q_{2 b}^{1 / 2}}\right)+\left(1-r_{2}\right) \\
& \times\left(-k q_{2 a}-2 q_{2 b}+l_{2}-k\left(q_{1 a}+q_{2 a}\right)-c_{2 b}\right. \\
&\left.\left.\quad-2 d_{2 b} q_{2 b}-h_{2} q_{2 a}+\frac{f_{2} q_{2 a}^{1 / 2}}{2 q_{2 b}^{1 / 2}}+k q_{1 a}\right)\right] . \\
& \times
\end{aligned}
$$

$q_{i j}^{\prime}$ denotes the unit-time advancement of variable $q_{i j}$. $\alpha_{1}, \alpha_{2}$, $\beta_{1}$, and $\beta_{2}$ are output adjustment parameters; for example, $\alpha_{1} q_{1 a}$ is the output speed of adjustment of $q_{1 a}$.

\section{The Nash Equilibrium and the Local Stability}

In order to investigate the Cournot-Nash equilibrium and its local stability, the Jacobian matrix of system (8) is given as following form:

$$
J=\left|\begin{array}{llll}
D_{11} & D_{12} & D_{13} & D_{14} \\
D_{21} & D_{22} & D_{23} & D_{24} \\
D_{31} & D_{32} & D_{33} & D_{34} \\
D_{41} & D_{42} & D_{43} & D_{44}
\end{array}\right|,
$$

where

$$
\begin{aligned}
D_{11}= & 1+\alpha_{1} \\
\times & \times r_{1}\left(-2 q_{1 a}+l_{1}-q_{2 a}-k\left(q_{1 b}+q_{2 b}\right)-k q_{1 b}-c_{1 a}\right. \\
& \left.\quad-2 d_{1 a} q_{1 a}-h_{1} q_{1 b}+\frac{f_{1}}{2 q_{1 a}^{1 / 2} q_{1 b}^{1 / 2}}\right)+\left(1-r_{1}\right)
\end{aligned}
$$




$$
\begin{aligned}
& \times\left(-2 q_{1 a}+l_{1}-k\left(q_{1 b}+q_{2 b}\right)-k q_{1 b}-c_{1 a}\right. \\
& \left.\left.-2 d_{1 a} q_{1 a}-h_{1} q_{1 b}+\frac{f_{1}}{2 q_{1 a}^{1 / 2} q_{1 b}^{1 / 2}}+k q_{2 b}\right)\right] \\
& +\alpha_{1} q_{1 a}\left[r_{1}\left(-2-2 d_{1 a}-\frac{f_{1}}{4 q_{1 a}^{3 / 2} q_{1 b}^{1 / 2}}\right)+\left(1-r_{1}\right)\right. \\
& \left.\times\left(-2-2 d_{1 a}-\frac{f_{1}}{4 q_{1 a}^{3 / 2} q_{1 b}^{1 / 2}}\right)\right], \\
& D_{12}=\alpha_{1} q_{1 a}\left[r_{1}\left(-2 k-h_{1}+\frac{f_{1}}{4 q_{1 a}^{1 / 2} q_{1 b}^{1 / 2}}\right)+\left(1-r_{1}\right)\right. \\
& \left.\times\left(-2 k-h_{1}+\frac{f_{1}}{4 q_{1 a}^{1 / 2} q_{1 b}^{1 / 2}}\right)\right], \\
& D_{13}=-\alpha_{1} q_{1 a} r_{1} \text {, } \\
& D_{14}=-\alpha_{1} q_{1 a} r_{1} k \text {, } \\
& D_{21}=\alpha_{2} q_{1 b}\left[r_{1}\left(-2 k-h_{1}+\frac{f_{1}}{4 q_{1 a}^{1 / 2} q_{1 b}^{1 / 2}}\right)+\left(1-r_{1}\right)\right. \\
& \left.\times\left(-2 k-h_{1}+\frac{f_{1}}{4 q_{1 a}^{1 / 2} q_{1 b}^{1 / 2}}\right)\right], \\
& D_{22}=1+\alpha_{2} \\
& \times\left[r _ { 1 } \left(-k q_{1 a}-2 q_{1 b}+l_{2}-q_{2 b}-k\left(q_{1 a}+q_{2 a}\right)-c_{1 b}\right.\right. \\
& \left.-2 d_{1 b} q_{1 b}-h_{1} q_{1 a}+\frac{f_{1}}{2 q_{1 a}^{1 / 2} q_{1 b}^{1 / 2}}\right)+\left(1-r_{1}\right) \\
& \times\left(-k q_{1 a}-2 q_{1 b}+l_{2}-k\left(q_{1 a}+q_{2 a}\right)-c_{1 b}\right. \\
& \left.\left.-2 d_{1 b} q_{1 b}-h_{1} q_{1 a}+\frac{f_{1}}{2 q_{1 a}^{1 / 2} q_{1 b}^{1 / 2}}+k q_{2 a}\right)\right] \\
& +\alpha_{2} q_{1 b}\left[r_{1}\left(-2-2 d_{1 b}-\frac{f_{1}}{4 q_{1 a}^{1 / 2} q_{1 b}^{3 / 2}}\right)+\left(1-r_{1}\right)\right. \\
& \left.\times\left(-2-2 d_{1 b}-\frac{f_{1}}{4 q_{1 a}^{1 / 2} q_{1 b}^{3 / 2}}\right)\right] \\
& D_{23}=-\alpha_{2} q_{1 b} r_{1} k \text {, } \\
& D_{24}=-\alpha_{2} q_{1 b} r_{1} \text {, } \\
& D_{31}=-\beta_{1} q_{2 a} r_{2}, \\
& D_{32}=-\beta_{1} q_{2 a} r_{2} k \text {, } \\
& D_{33}=1+\beta_{1} \\
& \times\left[r _ { 2 } \left(-2 q_{2 a}+l_{1}-q_{1 a}-k\left(q_{1 b}+q_{2 b}\right)-k q_{2 b}-c_{2 a}\right.\right. \\
& \left.-2 d_{2 a} q_{2 a}-h_{2} q_{2 b}+\frac{f_{2}}{2 q_{2 a}^{1 / 2} q_{2 b}^{1 / 2}}\right)+\left(1-r_{2}\right) \\
& \times\left(-2 q_{2 a}+l_{1}-k\left(q_{1 b}+q_{2 b}\right)-k q_{2 b}-c_{2 a}\right. \\
& \left.\left.-2 d_{2 a} q_{2 a}-h_{2} q_{2 b}+\frac{f_{2}}{2 q_{2 a}^{1 / 2} q_{2 b}^{1 / 2}}+k q_{1 b}\right)\right] \\
& +\beta_{1} q_{2 a}\left[r_{2}\left(-2-2 d_{2 a}-\frac{f_{2}}{4 q_{2 a}^{3 / 2} q_{2 b}^{1 / 2}}\right)+\left(1-r_{2}\right)\right. \\
& \left.\times\left(-2-2 d_{2 a}-\frac{f_{2}}{4 q_{2 a}^{3 / 2} q_{2 b}^{1 / 2}}\right)\right] \\
& D_{34}=\beta_{1} q_{2 a}\left[r_{2}\left(-2 k-h_{2}+\frac{f_{2}}{4 q_{2 a}^{1 / 2} q_{2 b}^{1 / 2}}\right)+\left(1-r_{2}\right)\right. \\
& \left.\times\left(-2 k-h_{2}+\frac{f_{2}}{4 q_{2 a}^{1 / 2} q_{2 b}^{1 / 2}}\right)\right], \\
& D_{41}=-\beta_{2} q_{2 b} r_{2} k \text {, } \\
& D_{42}=-\beta_{2} q_{2 b} r_{2} \text {, } \\
& D_{43}=\beta_{2} q_{2 b}\left[r_{2}\left(-2 k-h_{2}+\frac{f_{2}}{4 q_{2 b}^{1 / 2} q_{2 a}^{1 / 2}}\right)+\left(1-r_{2}\right)\right. \\
& \left.\times\left(-2 k-h_{2}+\frac{f_{2}}{4 q_{2 a}^{1 / 2} q_{2 b}^{1 / 2}}\right)\right] \\
& D_{44}=1+\beta_{2} \\
& \times\left[r _ { 2 } \left(-k q_{2 a}-2 q_{2 b}+l_{2}-q_{1 b}-k\left(q_{1 a}+q_{2 a}\right)-c_{2 b}\right.\right. \\
& \left.-2 d_{2 b} q_{2 b}-h_{2} q_{2 a}+\frac{f_{2}}{2 q_{2 a}^{1 / 2} q_{2 b}^{1 / 2}}\right)+\left(1-r_{2}\right) \\
& \times\left(-k q_{2 a}-2 q_{2 b}+l_{2}-k\left(q_{1 a}+q_{2 a}\right)-c_{2 b}\right. \\
& \left.\left.-2 d_{2 b} q_{2 b}-h_{2} q_{2 a}+\frac{f_{2}}{2 q_{2 a}^{1 / 2} q_{2 b}^{1 / 2}}+k q_{1 a}\right)\right] \\
& +\beta_{2} q_{2 b}\left[r_{2}\left(-2-2 d_{2 b}-\frac{f_{2} q_{2 a}^{1 / 2}}{4 q_{2 b}^{3 / 2}}\right)+\left(1-r_{2}\right)\right. \\
& \left.\times\left(-2-2 d_{2 b}-\frac{f_{2} q_{2 a}^{1 / 2}}{4 q_{2 b}^{3 / 2}}\right)\right] .
\end{aligned}
$$


In our system, multiproduct associated with the assumption of managerial delegation makes the computation of stability very dauntingly huge. The stability of this model is difficult to be analyzed in a general case. In order to get the Cournot Nash equilibrium point and find its local stable region, we prefer to set a value to each parameter:

$$
\begin{gathered}
c_{1 a}=0.15, \quad c_{1 b}=0.1, \quad c_{2 a}=0.2, \quad c_{2 b}=0.1, \\
l_{1}=6, \quad l_{2}=6, \quad d_{1}=0.5, \quad d_{2}=0.6, \\
d_{1 a}=0.85, \quad d_{1 b}=0.9, \quad d_{2 a}=0.95, \quad d_{2 b}=0.97, \\
h_{1}=0.5, \quad h_{2}=0.5, \quad f_{1}=0.8, \quad f_{2}=0.7, \\
k=0.2 ; \quad r_{1}=1.6, \quad r_{2}=1.6 .
\end{gathered}
$$

The initial values are chosen as $\left(q_{1 a}(0), q_{1 b}(0), q_{2 a}(0)\right.$, $\left.q_{2 b}(0)\right)=(0.5,0.5,0.5,0.5)$.

The Nash equilibrium of Cournot game is a state of output decision in which it is impossible to make any one player better off without making at least one player worse off. By computing $\partial \prod_{i} / \partial q_{i j}=0$, we can get the only positive Cournot Nash equilibrium point $q_{e}=$ $\left[q_{1 a}(0.9926), q_{1 b}(0.9667), q_{2 a}(0.8818), q_{2 b}(0.9103)\right]$ which is stable and has practical implications in economics (see [1, 35]). follows:

The characteristic equation of Jacobian matrix is as

$$
f(\lambda)=\lambda^{4}+A_{1} \lambda^{3}+A_{2} \lambda^{2}+A_{3} \lambda+A_{0}=0,
$$

where

$$
\begin{aligned}
A_{1}= & -4+3.87 \alpha_{1}+3.876 \alpha_{2}+3.617 \beta_{1}+3.759 \beta_{2}, \\
A_{2}= & -10.85 \beta_{1}-11.61 \alpha_{1}+13.6 \beta_{1} \beta_{2}+15 \alpha_{1} \alpha_{2} \\
& +11.76 \alpha_{1} \beta_{1}-11.63 \alpha_{2}+6+14.02 \alpha_{2} \beta_{1} \\
& +14.55 \alpha_{1} \beta_{2}-11.28 \beta_{2}+12.32 \alpha_{2} \beta_{2}, \\
A_{3}= & 44.19 \beta_{1} \beta_{2} \alpha_{1}-23.51 \alpha_{1} \beta_{1}+45.57 \alpha_{1} \alpha_{2} \beta_{1} \\
+ & 47.67 \alpha_{1} \alpha_{2} \beta_{2}-29.09 \alpha_{1} \beta_{2}-4+11.61 \alpha_{1}+11.63 \alpha_{2} \\
- & 30 \alpha_{1} \alpha_{2}+44.55 \alpha_{2} \beta_{1} \beta_{2}+11.28 \beta_{2}-24.64 \alpha_{2} \beta_{2} \\
- & 27.19 \beta_{1} \beta_{2}-28.04 \alpha_{2} \beta_{1}+10.85 \beta_{1}, \\
A_{0}= & +13.6 \beta_{1} \beta_{2}+14.55 \alpha_{1} \beta_{1}-44.19 \beta_{1} \beta_{2} \alpha_{1} \\
& -45.57 \alpha_{1} \alpha_{2} \beta_{1}+12.32 \alpha_{2} \beta_{2}-3.617 \beta_{1}-3.87 \alpha_{1} \\
- & 3.759 \beta_{2}+14.02 \alpha_{2} \beta_{1}+144.7 \alpha_{1} \alpha_{2} \beta_{1} \beta_{2} \\
& -44.55 \alpha_{2} \beta_{1} \beta_{2}-3.876 \alpha_{2}+15 \alpha_{1} \alpha_{2}+11.76 \alpha_{1} \beta_{1} \\
- & 47.67 \alpha_{1} \alpha_{2} \beta_{2} .
\end{aligned}
$$

According to Jury conditions [19], the sufficient and necessary conditions that $q_{e}$ is locally stable are

$$
\begin{gathered}
1+A_{1}+A_{2}+A_{3}+A_{0}>0, \\
1-A_{1}+A_{2}-A_{3}+A_{0}>0, \\
1-A_{0}^{2}>0, \\
\left(1-A_{0}^{2}\right)^{2}-\left(A_{3}-A_{1} A_{0}\right)^{2}>0, \\
{\left[\left(1-A_{0}^{2}\right)^{2}-\left(A_{3}-A_{1} A_{0}\right)^{2}\right]^{2}} \\
-\left[A_{2}\left(1-A_{0}\right)^{3}-\left(A_{1}-A_{3} A_{0}\right)\left(A_{3}-A_{1} A_{0}\right)\right]^{2}>0 .
\end{gathered}
$$

Therefore, the scope surrounded by $\left(\alpha_{1}, \alpha_{2}, \beta_{1}, \beta_{2}\right)$ which can satisfy the five conditions in (14) is the local region of $q_{e}$. The output will reach the Cournot Nash equilibrium point $q_{e}$ after rounds of games with random initial output within the local stable region.

Considering $\beta_{2}=0.34$, the local stable region at Cournot Nash equilibrium consisting of $\left(\alpha_{1}, \alpha_{2}, \beta_{1}\right)$ is shown in Figure 1. Similarly, we can fix other parameters and get the stable region at coordinate planes $\left(\alpha_{1}, \alpha_{2}, \beta_{2}\right),\left(\alpha_{1}, \beta_{1}, \beta_{2}\right)$, and $\left(\alpha_{2}, \beta_{1}, \beta_{2}\right)$. Here no discussions are made.

\section{The Numerical Simulation}

In this section, two intermittent routes to chaos are investigated in the system by numerical simulation.

4.1. Flip Bifurcation (Period-Doubling Bifurcation) and Its Intermittent Route to Chaos. We first restrict our experiment to the following set of parameters: $k=0.2, r=1.6, \alpha_{2}=\beta_{1}=$ $\beta_{2}=0.34$.

From Figures 2(a) and 2(b), the model has a unique equilibrium with $q_{e}=\left[q_{1 a}(0.9926), q_{1 b}(0.9667), q_{2 a}(0.8818)\right.$, $\left.q_{2 b}(0.9103)\right]$. Starting from a small value of $\alpha_{1}$, the system is in the stability region. When $\alpha_{1}$ increases, a loss of stability may occur via a Flip bifurcation (Period-doubling bifurcation). When the $\alpha_{1} \in(0.2083,0.5124)$, the output dynamic becomes unstable and chaotic behavior of output waves occurs after period 2, period 4 , and period 8 . If $\alpha_{1}$ is further increased $\left(\alpha_{1}>0.5124\right)$, the outputs become regular again. However as $\alpha_{1}$ is further increased $\left(\alpha_{1}>0.53\right)$, the outputs become once again chaotic. The abrupt change from chaos to period state is called tangential bifurcation and it is a kind of special bifurcation which is a route to chaos. The intermittent chaos is caused by tangential bifurcation in the market. Tangential bifurcation and intermittent chaos are all dynamic behaviors which are caused by the collision between chaotic attractor and periodic orbits. In the nonlinear dynamic of intermittent chaos, stable periodic state and chaotic state happen stochastically.

Figure 3 shows the enlarged drawing of the tangential bifurcation and the values of the maximum Lyapunov exponent with $\alpha_{1} \in[0.5,0.55]$. The system is in chaos if the 


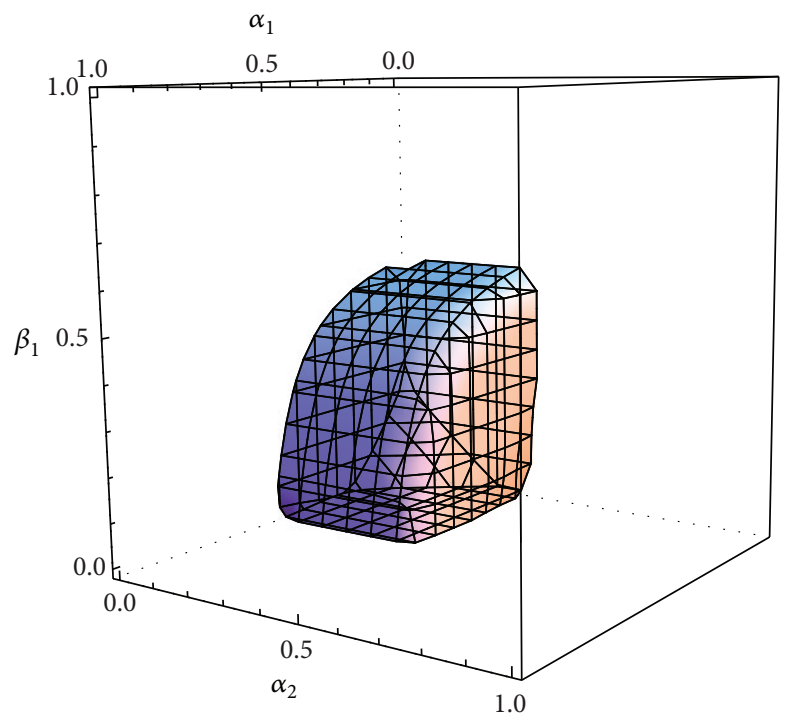

FIgURE 1: The local stable region with $\beta_{2}=0.34$.

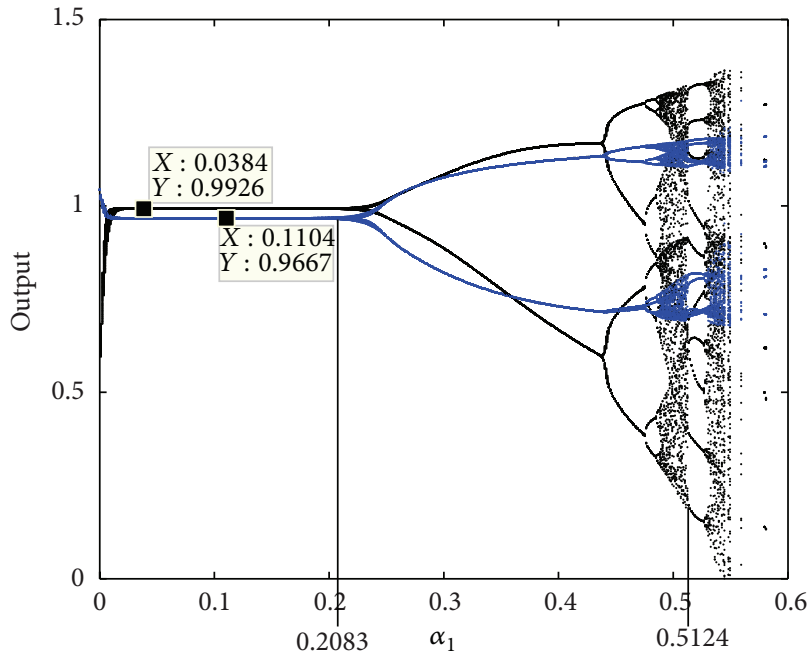

(a)

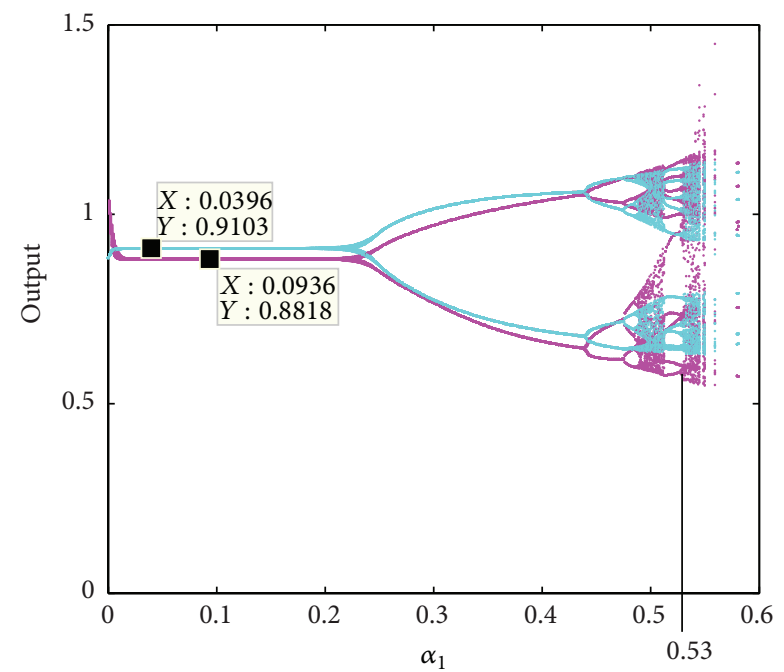

(b)

FIGURE 2: The bifurcation diagram with $k=0.2, r=1.6, \alpha_{2}=\beta_{1}=\beta_{2}=0.34$.

maximal Lyapunov exponent is bigger than zero, and the system is in steady period state if the maximal Lyapunov exponent is smaller than zero. From the change of the maximal Lyapunov exponent, the market is in chaotic state before tangential bifurcation. With the increase of $\alpha_{1}$, the market evolves into period state. Specially, in the period window, with the increase of $\alpha_{1}$, the periodic orbit which is caused by tangential bifurcation also shows bifurcation, and the structure of this bifurcation has a self-similar construction with the main bifurcation which evolves into chaos via Flip bifurcation. The system will show similar characteristics with changing $\alpha_{2}, \beta_{1}$, or $\beta_{2}$, and not in detail.

Let us analyze closely the characteristics of chaos that are observed in the parameter interval $\left(0.5<\alpha_{1}<0.55\right)$.
Figure 4(a) is time series curves of $q_{1 a}$ when $\alpha_{1}=0.512$ which is slightly smaller than the tangential bifurcation point $\alpha_{1}=0.5124$ and shows apparently the characteristic of intermittent chaos, namely, a long laminar phase (see $[20,21]$ ), where the output fluctuations behave regularly, and interrupted from time to time by chaotic bursts. Figure $4(\mathrm{~b})$ is the time series with $\alpha_{1}=0.52$ which is in period orbit. And Figures 5(a) and 5(b) are their phase portraits, respectively.

Above investigation shows that output fluctuations are characterized by phases of low volatility with small output changes and phases of high volatility, with large output changes. One possible reason for this phenomenon is the intermittency of the output fluctuations which is caused by rapid output adjustment speed. 


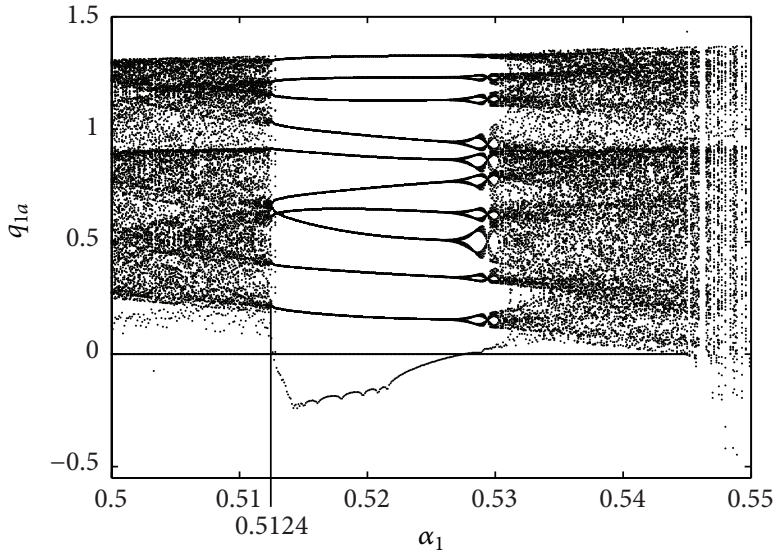

(a)

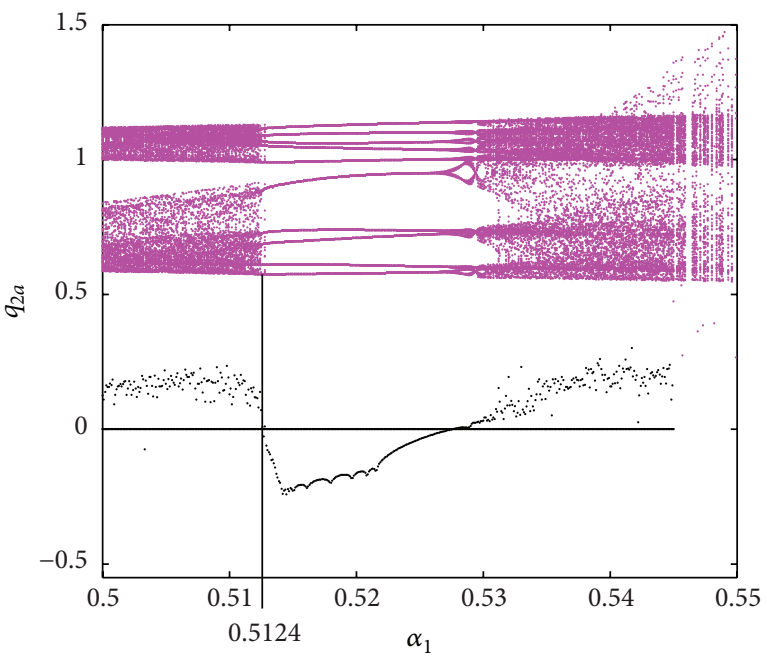

(c)

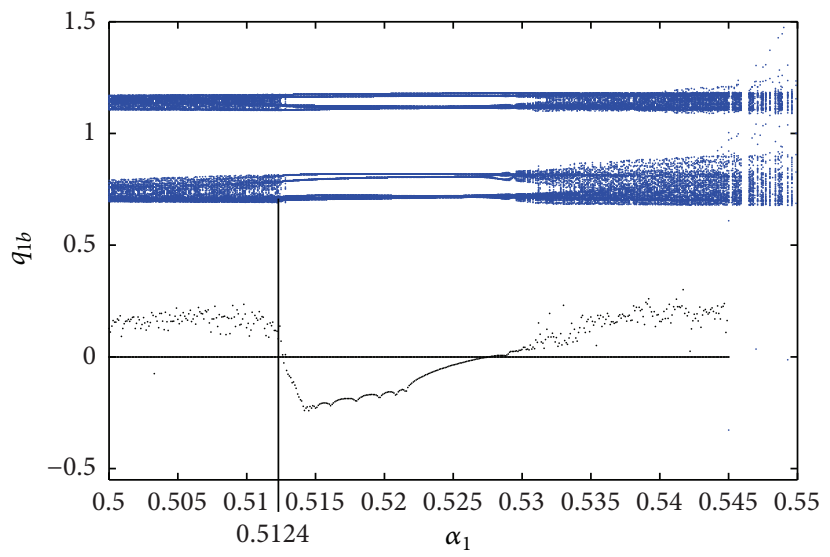

(b)

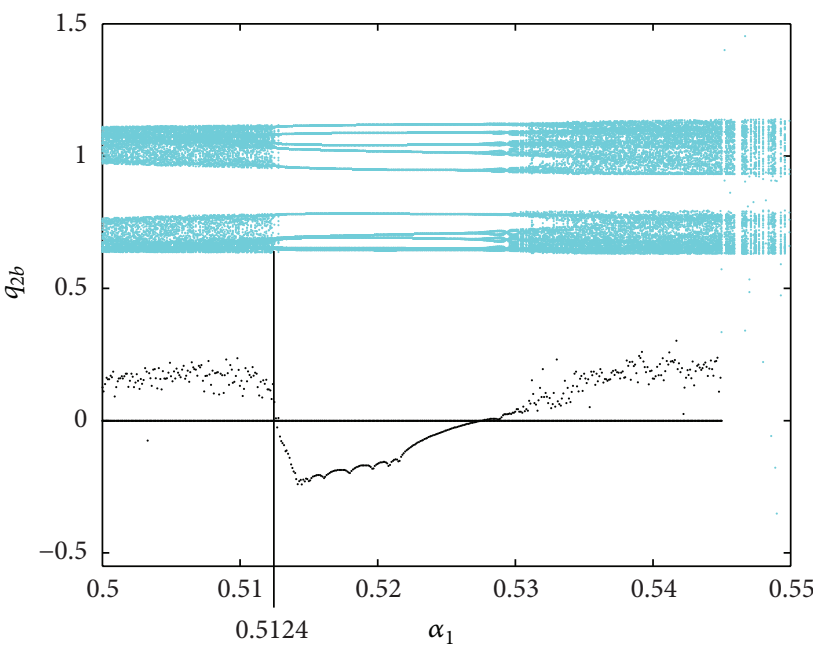

(d)

FIGURE 3: The enlarged drawing of tangential bifurcation and the maximum Lyapunov exponent.

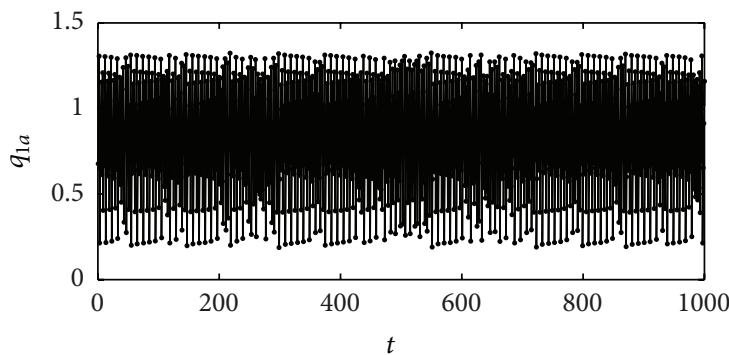

(a) $\alpha_{1}=0.512$

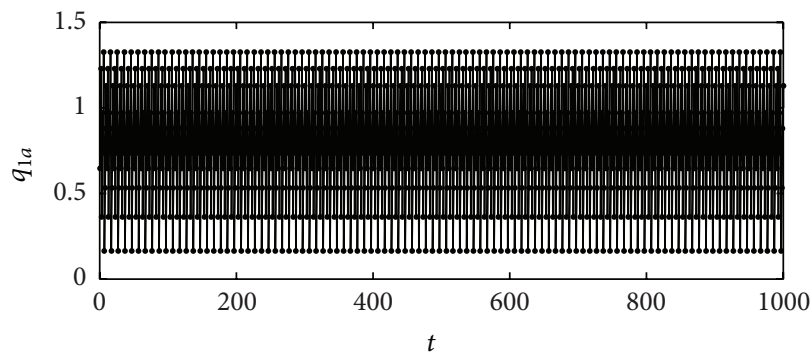

(b) $\alpha_{1}=0.52$

FIgURE 4: The time series of $q_{1 a}$.

\subsection{The Flip Bifurcation (Period-Doubling Bifurcation) Which} Contains Hopf Bifurcation and Its Intermittent Route to Chaos. Figure 6 is the bifurcation diagram when $k=-0.2, r=1.5$, $\alpha_{2}=0.35, \beta_{1}=\beta_{2}=0.348$ with $\alpha_{1} \in[0.3,0.45]$ and its maximum Lyapunov exponent. When $\alpha_{1} \in[0.3,0.3535)$, the system enters into chaos via period 2 orbit and Hopf bifurcation. When $\alpha_{1}>0.3535$, the tangential bifurcation occurs, and system enters into period 2 once again. With the increase of $\alpha_{1}$, system is in chaos when $\alpha_{1}>0.366$. When $\alpha_{1} \in(0.38,0.388)$, the system shows period doubling (Flip) orbit again, then entering the chaotic state when $\alpha_{1}>0.388$. 


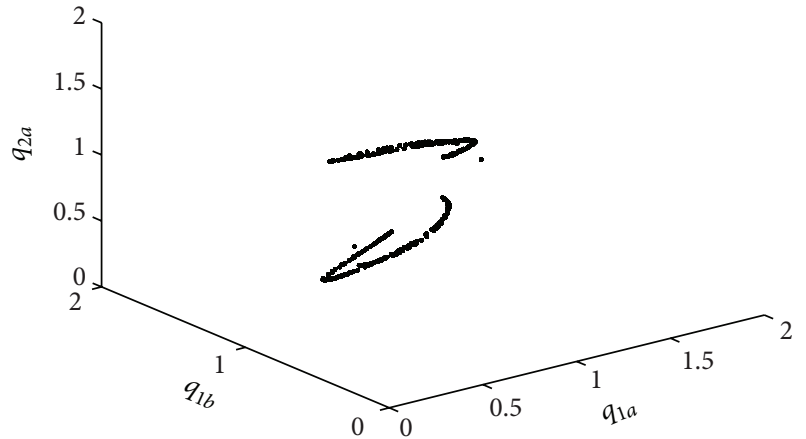

(a) $\alpha_{1}=0.512$

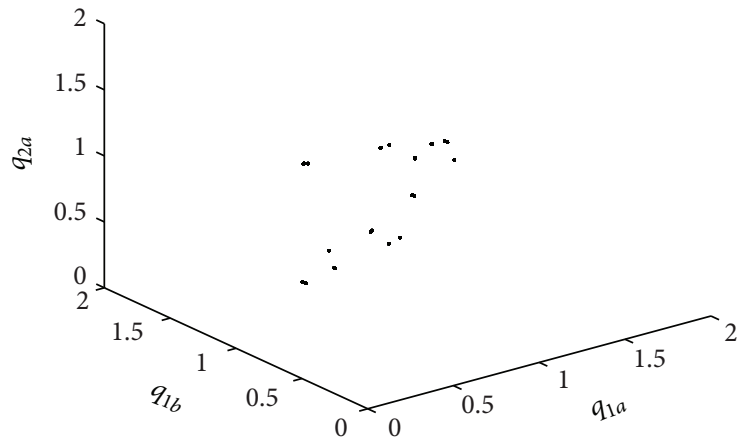

(b) $\alpha_{1}=0.52$

FIGURE 5: The 3-D phase portraits.

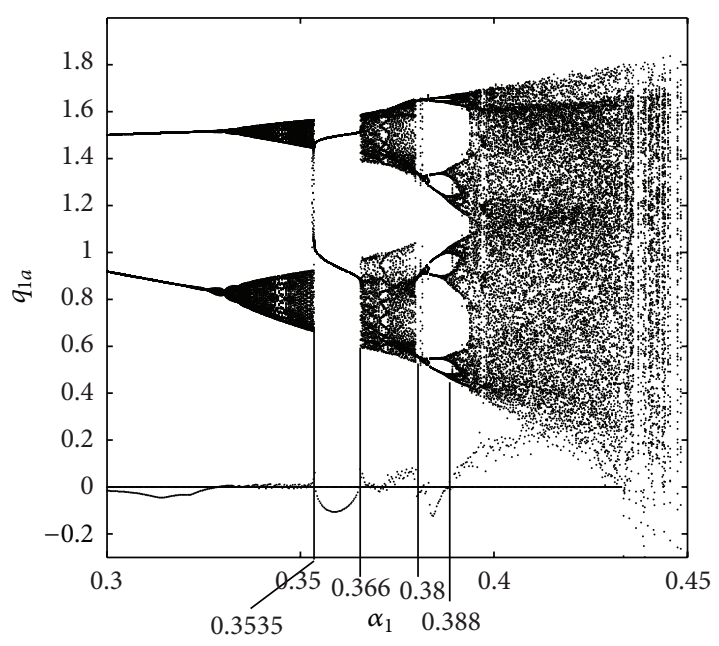

(a)

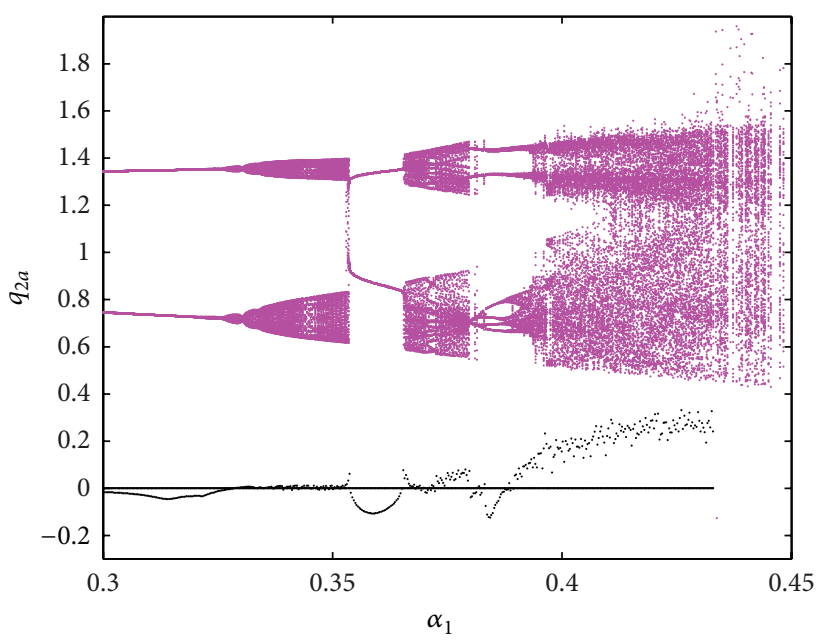

(c)

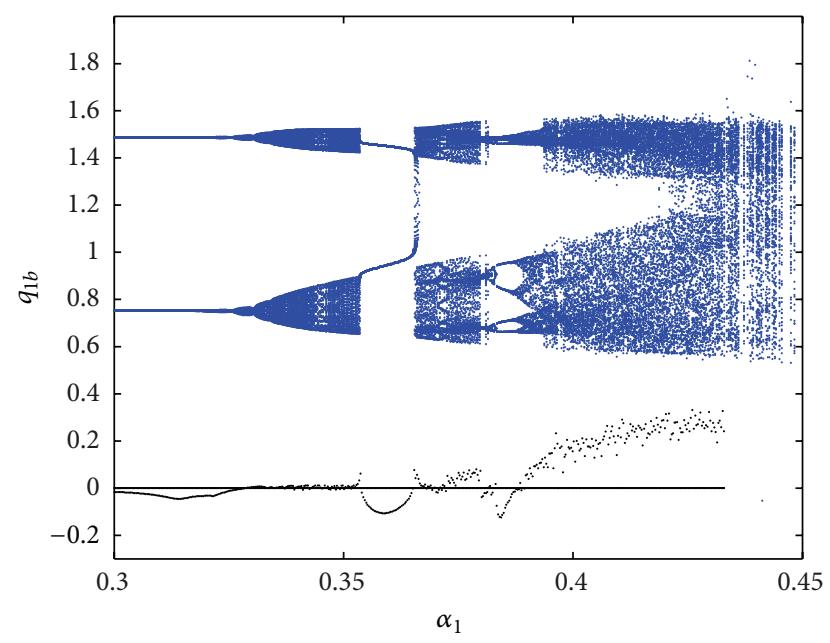

(b)

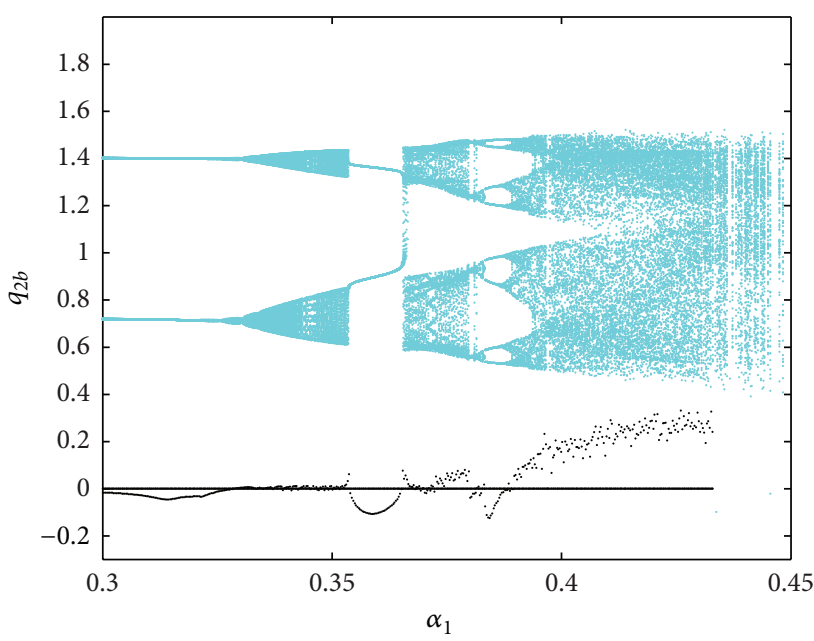

(d)

FIGURE 6: The bifurcation with $k=-0.2, r=1.5, \alpha_{2}=0.35, \beta_{1}=\beta_{2}=0.348$.

We take a value of $\alpha_{1}=0.353$ which is slightly smaller than 0.3535 (the tangential bifurcation point), the time series of $q_{1 a}$ exhibits nearly periodic laminar phases $[20,21]$ that are randomly interrupted by chaos bursts as Figure 7(a) describes, and Figure 8(a) is its phase portrait. Figure 7(b) shows time series of a period 2 orbit for $\alpha_{1}=0.354$ which is slightly bigger than $\alpha_{1}=0.3535$, and Figure $8(\mathrm{~b})$ shows its phase portrait. 


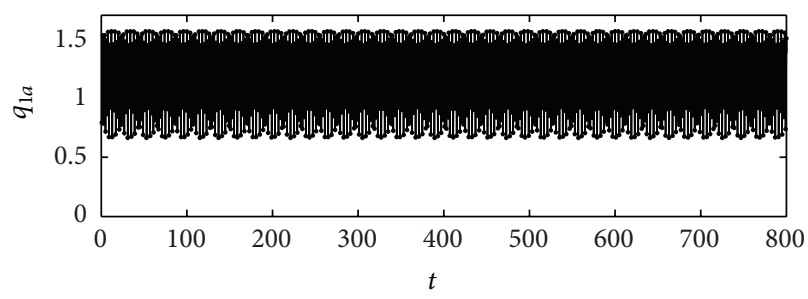

(a) $\alpha_{1}=0.353$

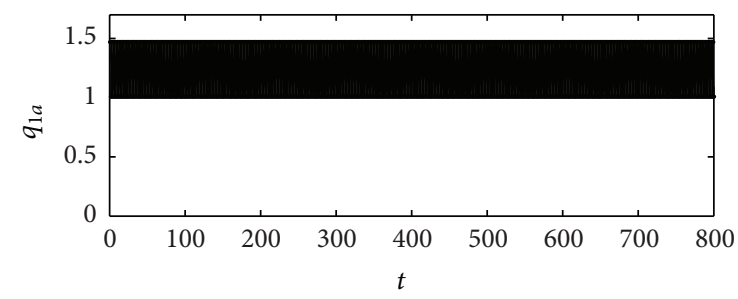

(b) $\alpha_{1}=0.354$

FIGURE 7: The time series of $q_{1 a}$.

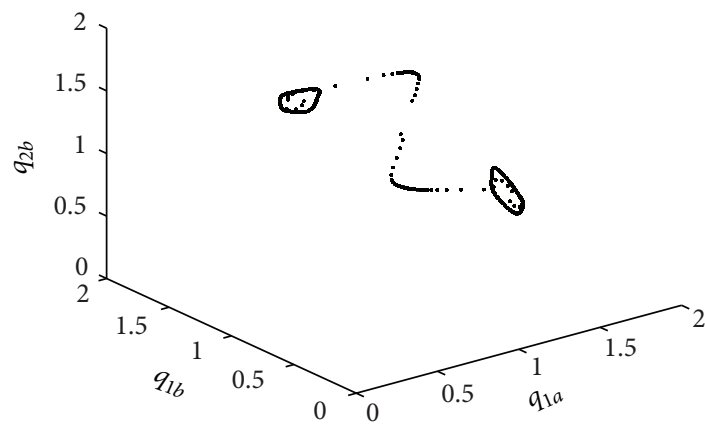

(a) $\alpha_{1}=0.353$

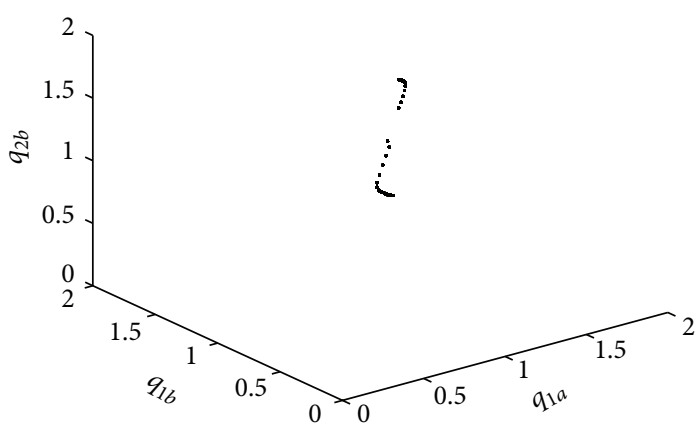

(b) $\alpha_{1}=0.354$

FIgURE 8: The phase portraits.

\section{Conclusion}

In this paper we propose a multiproduct Cournot duopoly model with relative profit delegation. The Cournot Nash equilibrium point and the local stability are analyzed. In particular, we show that the chaotic behavior is characterized by intermittency which is caused by tangential bifurcation. This means periodic state and unstable chaotic state appear alternately in the market. In real world, oligopoly market has been repeatedly disturbed by a series of severe output fluctuations which results tremendous economic losses of firms and the whole market. Our study suggests that the inappropriate output adjustment speed might be one reason that the output market becomes more vulnerable. The research provides the reference for enterprises and policy makers.

\section{Conflict of Interests}

The authors declare that there is no conflict of interests regarding the publication of this paper.

\section{Acknowledgments}

The authors thank the reviewers for their careful reading and providing some pertinent suggestions. The research was supported by the National Natural Science Foundation of China (no. 61273231), Doctoral Fund of Ministry of Education of China (Grant no. 20130032110073), and supported by Tianjin university innovation fund.

\section{References}

[1] H. W. Wang and J. H. Ma, "Complexity analysis of a CournotBertrand duopoly game model with limited information," Discrete Dynamics in Nature and Society, vol. 2013, Article ID 287371, 6 pages, 2013.

[2] F. Tramontana and A. E. A. Elsadany, "Heterogeneous triopoly game with isoelastic demand function," Nonlinear Dynamics, vol. 68, no. 1-2, pp. 187-193, 2012.

[3] J. H. Ma and X. S. Pu, "Complex dynamics in nonlinear triopoly market with different expectations," Discrete Dynamics in Nature and Society, vol. 2011, Article ID 902014, 12 pages, 2011.

[4] B. G. Xin, J. H. Ma, and Q. Gao, "Complex dynamics of an adnascent-type game model," Discrete Dynamics in Nature and Society, vol. 2008, Article ID 467972, 12 pages, 2008.

[5] J. H. Ma and H. L. Tu, "Complexity of a Duopoly game in the electricity market with delayed bounded rationality," Discrete Dynamics in Nature and Society, vol. 2012, Article ID 698270, 13 pages, 2012.

[6] Y. H. Guo and J. H. Ma, "Research on game model and complexity of retailer collecting and selling in closed-loop supply chain," Applied Mathematical Modelling, vol. 37, no. 7, pp. 5047-5058, 2013.

[7] L. Fanti, L. Gori, and M. Sodini, "Nonlinear dynamics in a Cournot duopoly with relative profit delegation," Chaos, Solitons \& Fractals, vol. 45, no. 12, pp. 1469-1478, 2012.

[8] C. Fershtman and K. L. Judd, "Equilibrium incentives in oligopoly," American Economic Review, vol. 77, no. 5, pp. 927940, 1987. 
[9] S. D. Sklivas, "The strategic choice of managerial incentives," RAND Journal of Economics, vol. 18, no. 3, pp. 452-458, 1987.

[10] J. Vickers, "Delegation and the theory of the firm," Economic Journal, vol. 95, supplement, pp. 138-147, 1985.

[11] T. Jansen, A. van Lier, and A. van Witteloostuijn, "A note on strategic delegation: the market share case," International Journal of Industrial Organization, vol. 25, no. 3, pp. 531-539, 2007.

[12] R. A. Ritz, "Strategic incentives for market share," International Journal of Industrial Organization, vol. 26, no. 2, pp. 586-597, 2008.

[13] V. S. Fumas, "Relative performance evaluation of management. The effects on industrial competition and risk sharing," International Journal of Industrial Organization, vol. 10, no. 3, pp. 473489, 1992.

[14] N. Miller and A. Pazgal, "Relative performance as a strategic commitment mechanism," Managerial and Decision Economics, vol. 23, no. 2, pp. 51-68, 2002.

[15] S. C. Maurice and C. R. Thomas, Managerial Economics, China Machine Press, Beijing, China, 2003.

[16] T. Dubiel-Teleszynski, "Nonlinear dynamics in a heterogeneous duopoly game with adjusting players and diseconomies of scale," Communications in Nonlinear Science and Numerical Simulation, vol. 16, no. 1, pp. 296-308, 2011.

[17] D. Hanly and K. C. K. Cheung, "Market structure of multiproduct firms under free entry," Economics Letters, vol. 61, no. 2, pp. 159-163, 1998.

[18] K. Basu, "Stackelberg equilibrium in oligopoly: an explanation based on managerial incentives," Economics Letters, vol. 49, no. 4, pp. 459-464, 1995.

[19] T. Puu, Attractors, Bifurcations and Chaos: Nonlinear Phenomena in Economics, Springer, Berlin, Germany, 2000.

[20] T. Kaizoji, "Intermittent chaos in a model of financial markets with heterogeneous agents," Chaos, Solitons and Fractals, vol. 20, no. 2, pp. 323-327, 2004.

[21] R. A. Miranda, E. L. Rempel, A. C.-L. Chian, and F. A. Borotto, "Intermittent chaos in nonlinear wave-wave interactions in space plasmas," Journal of Atmospheric and Solar-Terrestrial Physics, vol. 67, no. 17-18, pp. 1852-1858, 2005. 


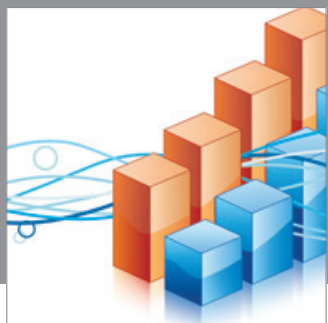

Advances in

Operations Research

mansans

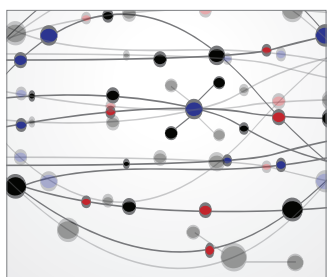

The Scientific World Journal
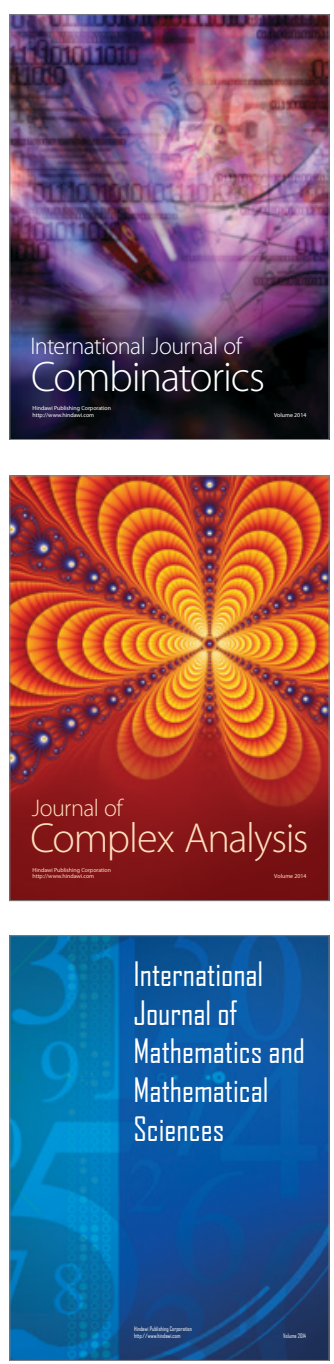
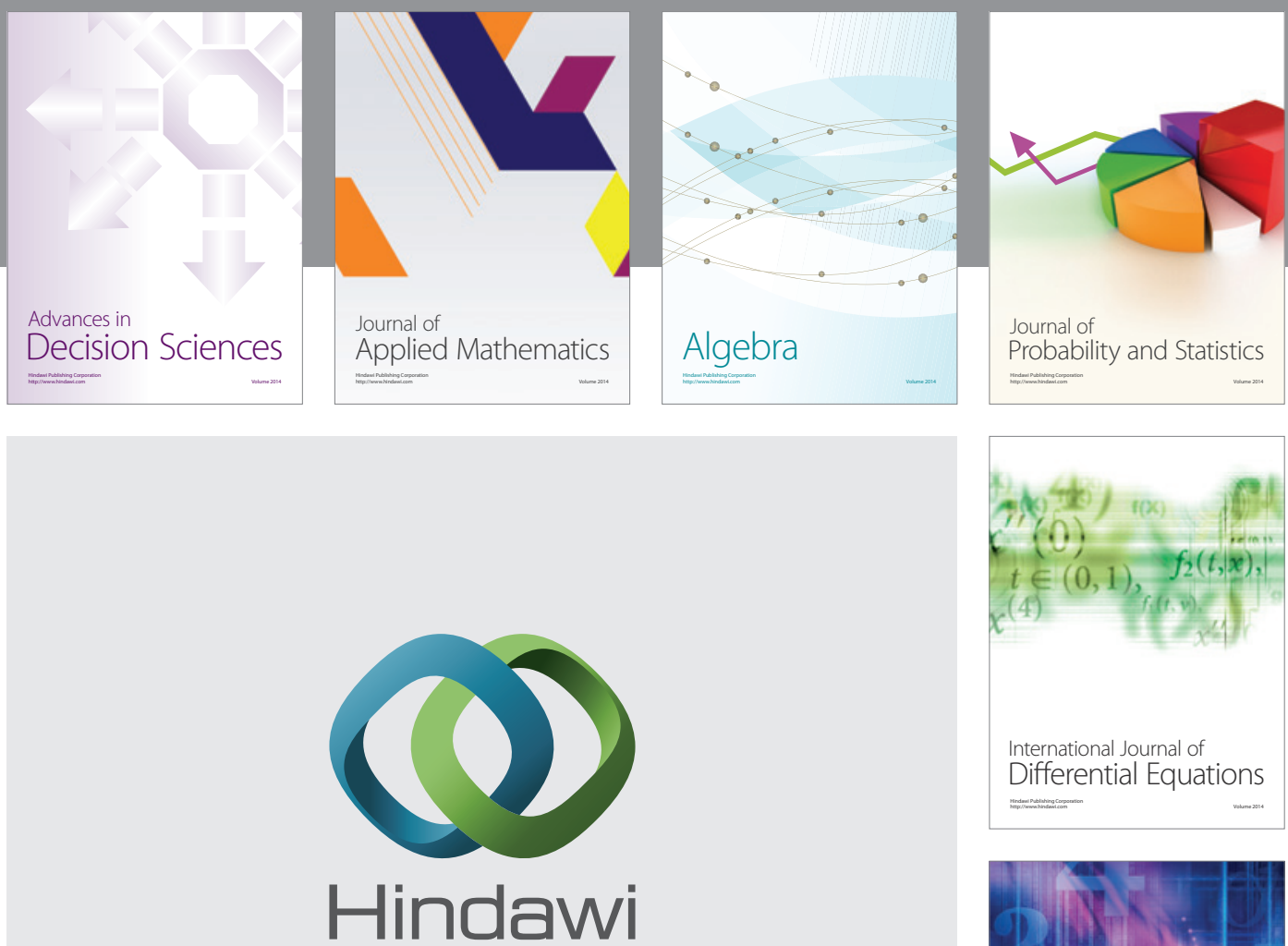

Submit your manuscripts at http://www.hindawi.com
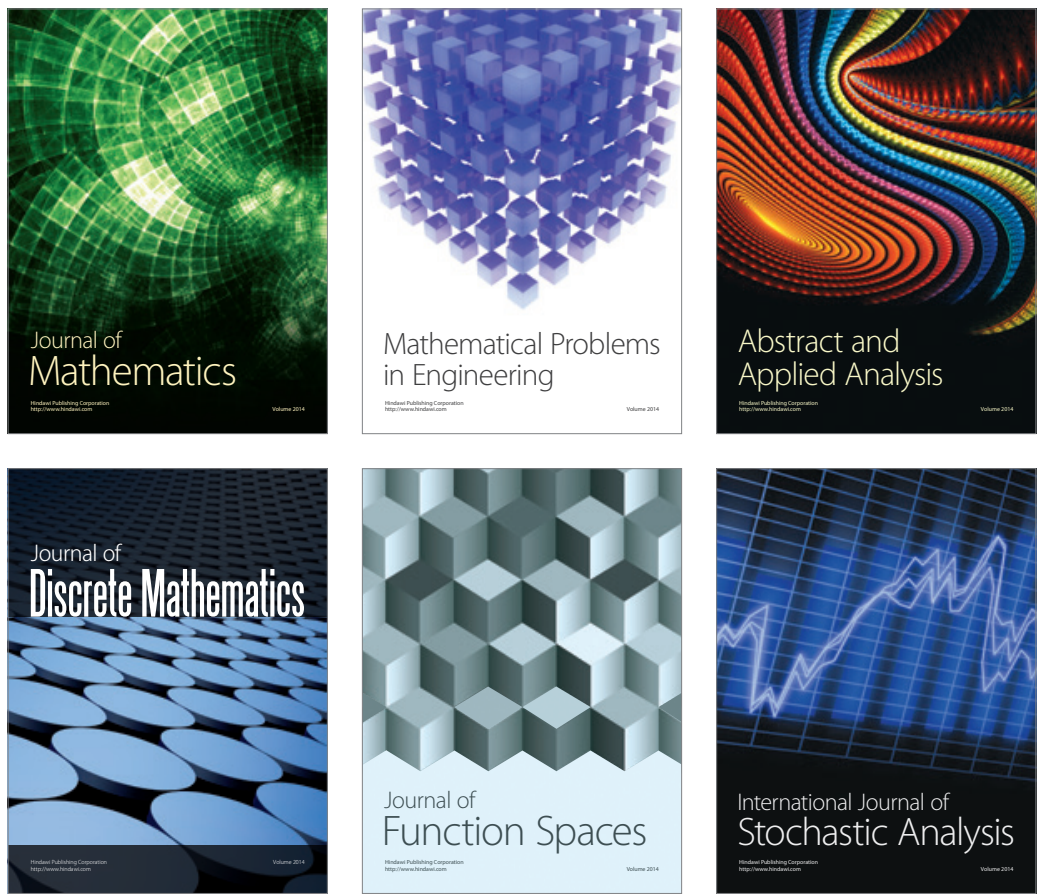

Journal of

Function Spaces

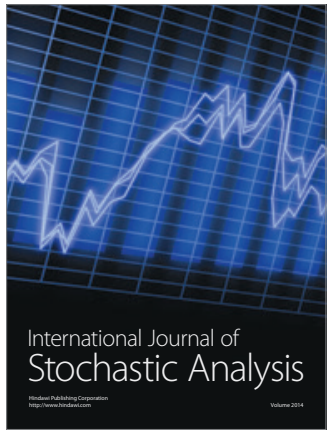

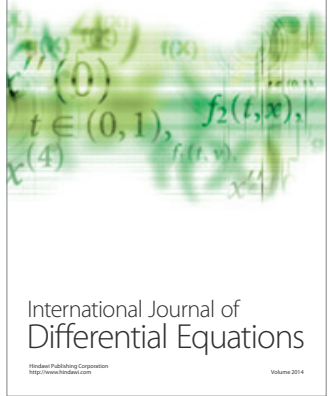
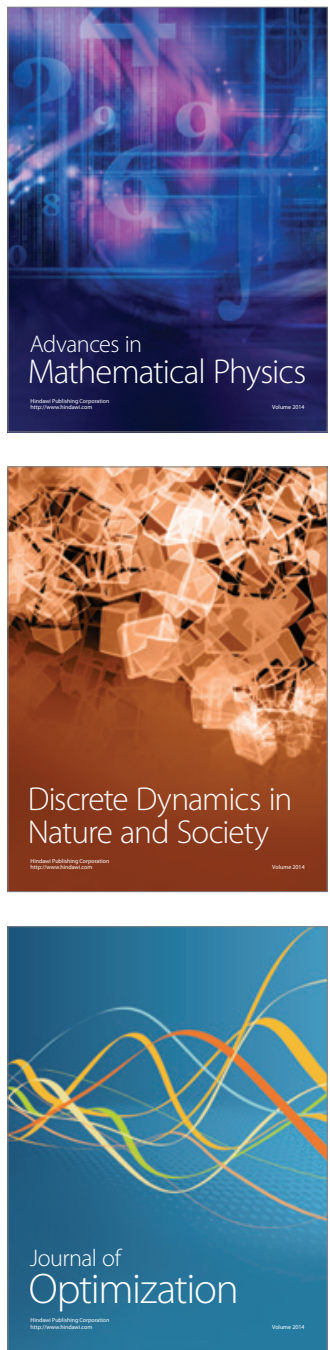